\title{
Paediatric emergency department attendances during COVID-19 and SARS in Singapore
}

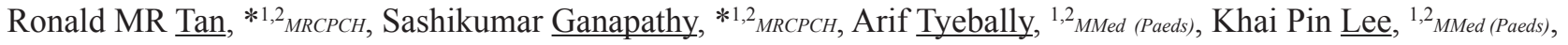

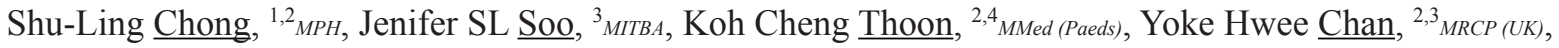
Kee Chong $\underline{\mathrm{Ng}},{ }^{1,2}$ FRCPCH

\begin{abstract}
Introduction: We evaluated the impact of public health measures on paediatric emergency department attendances during the COVID-19 and severe acute respiratory syndrome (SARS) outbreaks in Singapore.

Methods: Between 1 January 2020 and 31 July 2020, we retrospectively reviewed paediatric emergency department attendances and admissions in a tertiary paediatric hospital in Singapore before and after a national lockdown to combat the spread of COVID-19 in Singapore. Hospital attendances and admissions were compared with data from a corresponding period in 2019 (1 January 2019 to 31 July 2019), as well as during and after the SARS outbreak (1 January 2003 to 31 December 2004).

Results: Compared with a corresponding non-outbreak period, emergency department attendances decreased in line with nationwide public health measures during the COVID-19 and SARS outbreaks (2020 and 2003 respectively), before increasing gradually following lifting of restrictions, albeit not to recorded levels before these outbreaks. During the COVID-19 outbreak, mean daily attendances decreased by $40 \%$, from 458 per day in January-July 2019, to 274 per day in January-July 2020. The absolute number of hospital inpatient admissions decreased by $37 \%$ from January-July $2019(19,629)$ to January-July $2020(12,304)$. The proportion of emergency department attendances requiring admission remained similar: 20\% in January-July 2019 and 21\% in January-July 2020.

Conclusion: Nationwide public health measures in Singapore have had an impact on paediatric emergency department attendances and hospital inpatient admissions. Data from this study could inform planning and resource allocation for emergency departments in Singapore and internationally.
\end{abstract}

Ann Acad Med Singap 2021;50:126-34

Keywords: COVID-19, paediatric emergency department, public health measures, SARS

\section{INTRODUCTION}

Coronavirus disease 2019 (COVID-19) was declared a pandemic by the World Health Organization (WHO) on 11 March $2020,{ }^{1}$ with over 110 million cumulative cases worldwide to date ${ }^{2}$ and a case fatality rate of approximately 1\%. ${ }^{3}$ In comparison, the 2003 outbreak of severe acute respiratory syndrome (SARS) had 8,422 cumulative cases worldwide and a higher case fatality rate of $11 \%{ }^{4}$ While the high transmissibility and broad clinical spectrum of SARS-coronavirus-2 (SARSCoV-2) may render COVID-19 more difficult to eradicate than SARS, stringent physical distancing and hygiene measures are effective in reducing the effective transmission coefficient and associated mortality. ${ }^{3}$

Initial reports of paediatric COVID-19 infection described a milder course of illness than in adults. ${ }^{5,6} \mathrm{In}$ May 2020, a novel Kawasaki-like shock syndrome associated with COVID-19, designated as multisystem inflammatory syndrome in children (MIS-C), was described in Europe and North America. ${ }^{7-9}$ This severe paediatric disease phenotype has not been observed in Asia as yet. ${ }^{10,11}$

The first imported case of COVID-19 in Singapore was detected on 23 January 2020. ${ }^{12}$ With Singapore's national

\footnotetext{
${ }^{1}$ Department of Emergency Medicine, KK Women's and Children's Hospital, Singapore

${ }^{2}$ Duke-NUS Medical School, Singapore

${ }^{3}$ Division of Medicine, KK Women's and Children's Hospital, Singapore

${ }^{4}$ Department of Paediatric Medicine, KK Women's and Children's Hospital, Singapore

Correspondence: Dr Ronald MR Tan, Department of Emergency Medicine, KK Women’s and Children's Hospital, 100 Bukit Timah Road, Singapore 229899.

Email: Ronald.tan.m.r@singhealth.com.sg

*Joint first authors
} 
perspective on the importance of pandemic preparedness shaped in 2003 by SARS, the country has implemented a nationwide public health response strategy involving early identification and isolation of COVID-19 cases to reduce the risk of further transmission. ${ }^{13-15}$ Given the increasing international and local spread of COVID-19 from February 2020 onwards, progressive restrictions in population activities and movement culminated in a comprehensive set of safe distancing measures, referred to as the "circuit breaker". ${ }^{16-19}$ This was followed by a period of gradual relaxation of circuit breaker measures in May 2020 as community-acquired COVID-19 infections decreased $^{20,21}$ (Table 1).

Understanding the evolution of paediatric emergency department (ED) attendances will facilitate both paediatric ED and the hospital's planning and resource allocation in the COVID-19 and post-COVID-19 period. We therefore evaluated the impact of nationwide public health measures on paediatric ED attendances during the ongoing COVID-19 pandemic, comparing attendances and hospital admissions in 2020 as Singapore went through the pre-COVID-19 period to the COVID-19 period, with the corresponding periods in 2019 (a representative non-outbreak year), and 2003-2004 during and after the SARS outbreak - the only other emerging infectious disease outbreak in Singapore of comparable magnitude. ${ }^{22,23}$ Additionally, we compared the number and severity of confirmed Kawasaki disease patients admitted to our institution in the first 7 months of 2019 and 2020.

\section{METHODS}

This is a retrospective review of paediatric ED attendances during the study periods of 1 January 2003-31 December 2004, 1 January-31 July 2019, and 1 January-31 July 2020. KK Women's and Children's Hospital is an 830-bed tertiary hospital in Singapore, with 500 paediatric inpatient beds. As part of the

Table 1. Nationwide public health measures implemented in Singapore to prevent imported cases and local transmission of COVID-19

\begin{tabular}{|c|c|c|}
\hline Date (2020) & Measures taken & Details of measures \\
\hline 7 February & $\begin{array}{l}\text { National risk assessment } \\
\text { stepped up to } \\
\text { DORSCON Orange }^{16}\end{array}$ & $\begin{array}{l}\text { - Cancellation or deferral of non-essential large-scale events } \\
\text { - Daily workplace health checks including temperature-taking } \\
\text { - Hospital implementation of temperature screening for visitors and segregation of pneumonia patients } \\
\text { - Suspension of inter-school activities such as national school games and camps } \\
\text { - Limits to number of visitors to preschools and eldercare services }\end{array}$ \\
\hline 24 March & Travel ban ${ }^{17}$ & - All short-term visitors (from anywhere in the world) not allowed to enter or transit through Singapore \\
\hline 7 April & Circuit breaker (CB) $1^{18}$ & $\begin{array}{l}\text { - Closure of most workplaces except those providing essential services } \\
\text { - Schools closed and lessons moved online } \\
\text { - Social gatherings both in private and public spaces prohibited } \\
\text { - Dining-in at restaurants disallowed } \\
\text { - Interim measure on } 14 \text { April: compulsory wearing of face masks outside the house }\end{array}$ \\
\hline 21 April & $\mathrm{CB} 2^{19}$ & $\begin{array}{l}\text { - Extension of original circuit breaker measures } \\
\text { - Number of essential businesses allowed to operate further reduced } \\
\text { - Entry restrictions at wet markets and supermarkets to reduce crowding } \\
\text { - Mid-year school holidays brought forward from June to May }\end{array}$ \\
\hline 5 May & $1^{\text {st }}$ easing of $\mathrm{CB}^{20}$ & $\begin{array}{l}\text { - Traditional Chinese medicine practitioners allowed to administer acupuncture for pain management } \\
\text { - Residents of strata-titled residential buildings allowed to exercise in common areas with safe } \\
\text { distancing measures }\end{array}$ \\
\hline 12 May & $2^{\text {nd }}$ easing of $\mathrm{CB}^{20}$ & - Opening of home-based food businesses, selected food retail, manufacturing, hairdressers/barbers \\
\hline 2 June & Phase 1 of Post-CB ${ }^{21}$ & $\begin{array}{l}\text { - Resumption of manufacturing, motor vehicle servicing } \\
\text { - Visits to parents/grandparents allowed } \\
\text { - Places of worship reopened } \\
\text { - Gradual re-opening of schools }\end{array}$ \\
\hline
\end{tabular}

DORSCON: Disease Outbreak Response System CONdition; CB: Circuit breaker

Superscript numbers: Refer to REFERENCES 


\section{CLINICAL IMPACT}

\section{What is New}

- Public health measures have had an impact on paediatric emergency department attendances and hospital admissions in Singapore.

- These findings are derived by comparing hospital-based registry data at KK Women's and Children's Hospital during COVID-19 in 2020 and SARS in 2003.

\section{Clinical Implications}

- Paediatric emergency department attendances decreased in line with national lockdown periods in Singapore, followed by a prolonged phase before increasing towards pre-pandemic levels.

- Data from this study could have implications for planning of future health services and resource allocation to meet the emergent manpower needs during a pandemic.

rapid response to cater for the demands of COVID-19 screening, isolation and admissions, the hospital's Children's Emergency (CE) created new areas to segregate patients based on their risk category. ${ }^{24}$

- High-risk area: "Suspect" cases based on Ministry of Health criteria for symptoms and travel history were managed in the existing $\mathrm{CE}$ negative-pressure isolation facility.

- Intermediate-risk area: "At-risk" cases with fever or acute respiratory symptoms were seen in the main area.

- Low-risk area: "Clean" cases with no travel or contact history, fever or acute respiratory symptoms were seen in a new tent facility built to increase CE capacity.

The CE triages patients according to their severity of illness at presentation into $\mathrm{P} 1, \mathrm{P} 2$ and $\mathrm{P} 3$ cases..$^{25} \mathrm{P} 1$ cases (highest acuity) have unstable physiological parameters requiring immediate medical attention at the resuscitation area. P2 are acute cases that require medical attention urgently within the next 15 minutes (P2+) or 60 minutes (P2). P3 cases (lowest acuity) are considered less urgent and may wait in turn for consultation.

Information on $\mathrm{CE}$ attendances were extracted from the hospital electronic medical records for the following: patients' CE location (high, intermediate and low-risk areas), triage category (P1, P2 and $\mathrm{P} 3$ ) and diagnosis category (trauma, non-trauma); disposition from $\mathrm{CE}$ including discharge and admission; and inpatient discharge diagnosis of Kawasaki disease. Data were analysed using descriptive statistics. Ethics approval from the SingHealth Centralised Institutional Review Board (reference 2020/2760) was obtained.

\section{RESULTS}

\section{Overall CE attendance}

During the COVID-19 outbreak in 2020, CE total daily attendances decreased progressively from 400-600 attendances per day in January to under 200 per day in April, with successive circuit breaker measures. The number then gradually increased in tandem with relaxation of circuit breaker measures, translating into a mean daily attendance of 274 (Fig. 1, top row). The 2003 SARS outbreak saw a similar attendance trend, decreasing from around 400 attendances per day at the start of the year, to under 100 per day in April 2003 following the closure of schools, then gradually increasing, with a mean daily attendance of 232 (Fig. 1, bottom row). These trends in the outbreak years of 2020 and 2003 contrasted with a relatively stable mean daily attendance of 458 throughout January-July 2019 (Fig. 1, middle row) - a $40 \%$ decrease in total CE attendances from January-July 2019 compared to January-July 2020.

Following the 2003 SARS outbreak and the eradication of SARS in Singapore by July 2003, CE attendances only stabilised by September 2003 and remained relatively constant throughout 2004 at a new baseline slightly lower than pre-SARS levels (Fig. 2).

\section{CE attendance stratified by location, triage category and diagnosis category}

When stratified by location (Fig. 3), monthly CE attendances showed a stable pattern throughout the first half of 2019. In 2020, the number of intermediate-risk area patients decreased while the number of low-risk patients increased, stabilising at approximately similar numbers in each area from April 2020 onwards; for high-risk area patients there was a spike in March 2020 with numbers decreasing in subsequent months. Outpatient COVID-19 nasopharyngeal swab polymerase chain reaction (PCR) testing in $\mathrm{CE}$ was progressively introduced from February 2020, with a surge in testing of asymptomatic paediatric close contacts of confirmed COVID-19 cases, who were proactively identified and brought to CE for testing from early March 2020 onwards. These paediatric close contacts were seen in the high-risk area and contributed to the surge in attendance in March 2020. 


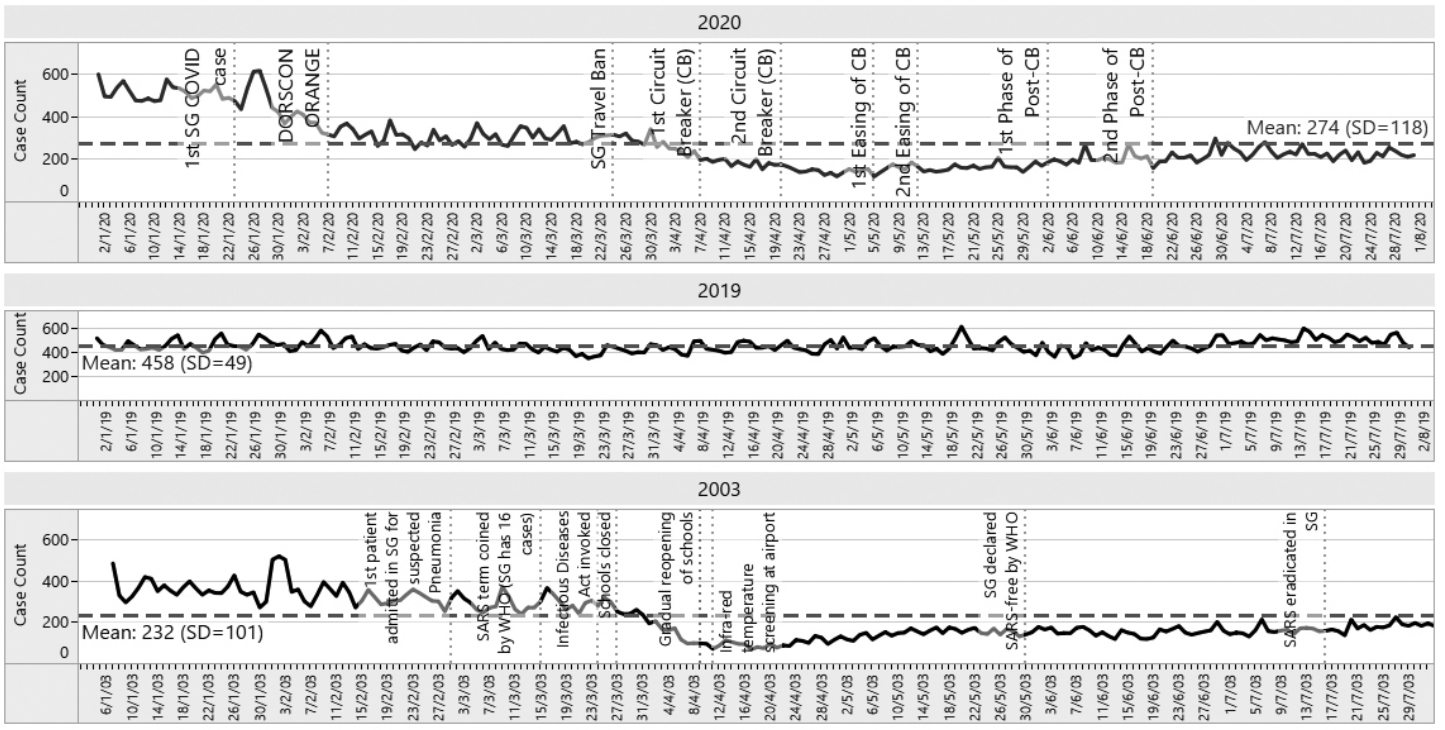

Fig. 1. Children's Emergency daily attendance from January-July 2020 (top row), 2019 (middle row) and 2003 (bottom row). The timing of key events during the 2020 COVID-19 and 2003 SARS outbreaks are shown on their respective graphs. DORSCON: Disease Outbreak Response System CONdition; SG: Singapore; WHO: World Health Organization

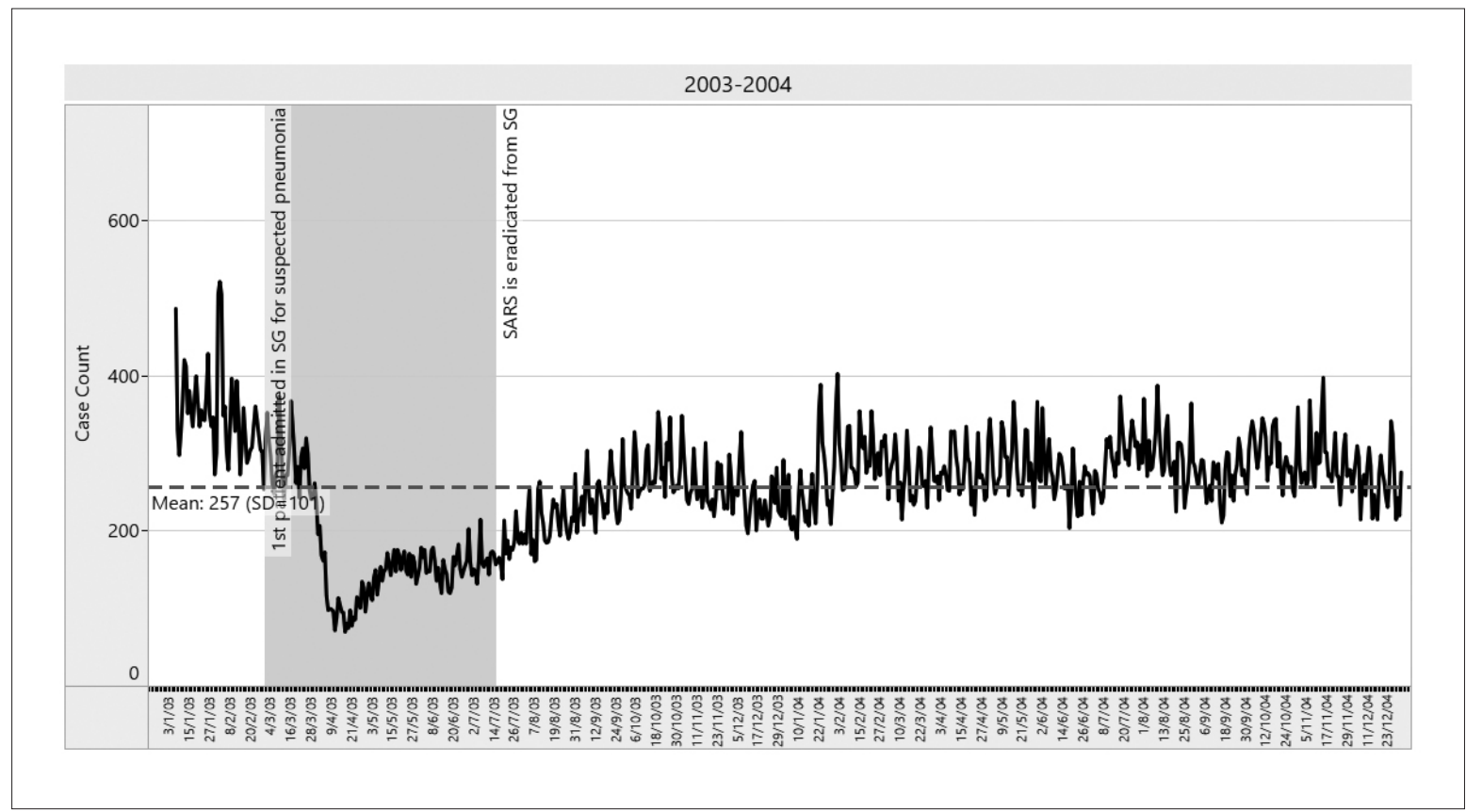

Fig. 2. Children's Emergency daily attendance January 2003-December 2004, including key events during the 2003 SARS outbreak. SG: Singapore

The total CE attendance in January-July 2020 (58,272 patients) was less compared to January-July 2019 (97,153 patients). However, a similar triage category distribution was observed, with the majority of $\mathrm{CE}$ attendances categorised as P2 (52\% in 2019 versus 51\% in 2020), followed by P3 (44\% in 2019 vs 46\% in 2020), and a small number of P1 attendances $(2.5 \%$ in both 2019 and 2020).

Further stratifying P1 attendances by diagnosis category (trauma and non-trauma) between January-July 2019 


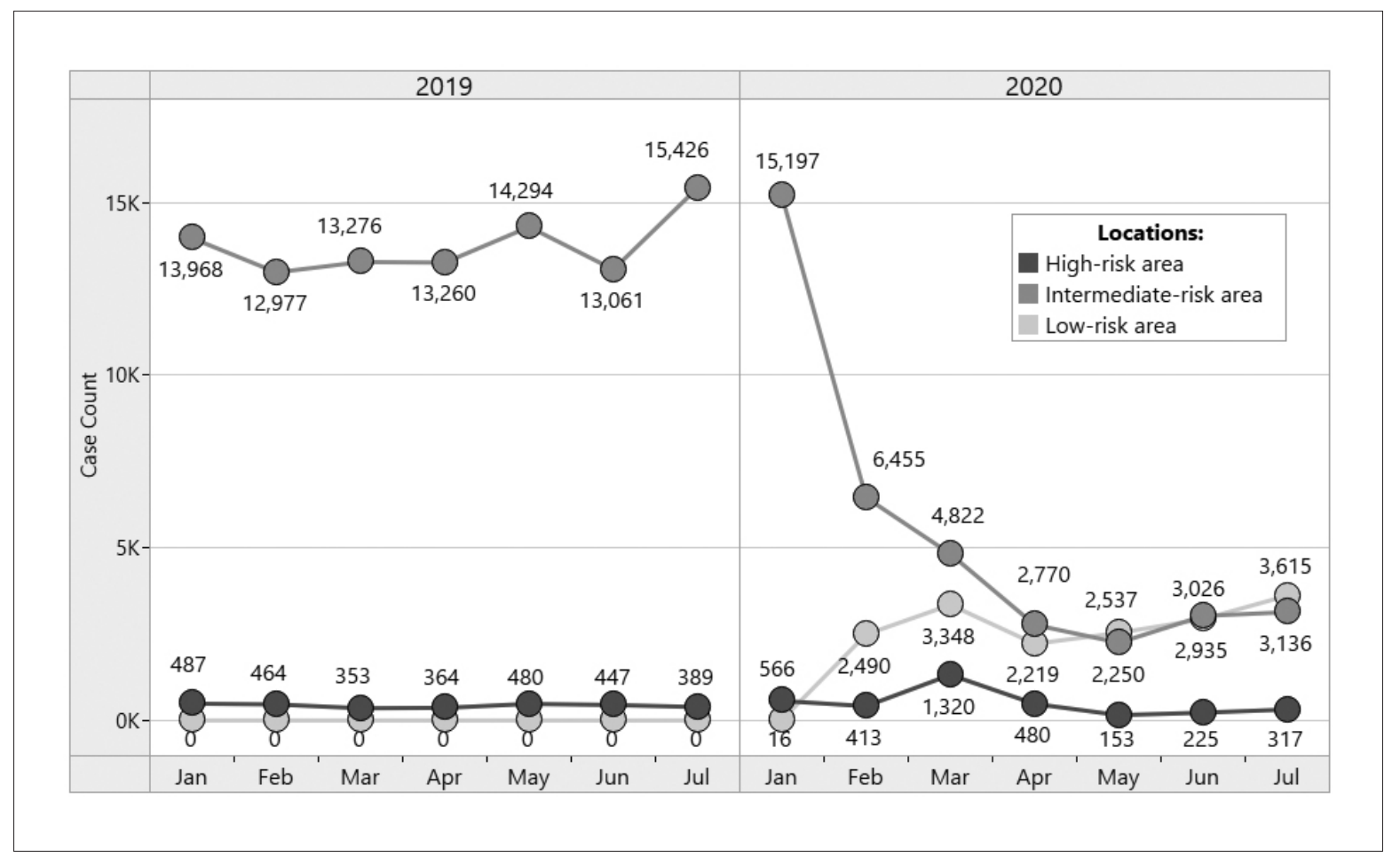

Fig. 3. Children's Emergency monthly attendance from January-July 2019 (left) and January-July 2020 (right), stratified by location (High, Intermediate and Low-risk areas). Low-risk area data started in early 2020 when the tent facility was built.

and 2020 (Table 2) showed that trauma cases comprised $12.5 \%$ of all $\mathrm{P} 1$ attendances in 2019 , compared to $13.7 \%$ in 2020; non-trauma cases made up $87.5 \%$ of P1 attendances in 2019 , versus $86.3 \%$ in 2020 . While the top 10 specific diagnoses in both trauma and non-trauma categories were broadly similar between 2019 and 2020, there was an increase for P1 trauma attendances in both number and proportion of burns and scalds from $18(6 \%)$ in 2019 to $25(13 \%)$ in 2020. Conversely, for P1 nontrauma attendances, there was a decrease in number and proportion of all-cause respiratory-related attendances among the top 10 diagnoses, from 936 (44\%) in 2019 to $399(32 \%)$ in 2020 (Table 2).

As to the relative proportions of total $\mathrm{CE}$ attendances classified as trauma and non-trauma cases, JanuaryJuly 2020 had a slight increase in proportion of trauma cases (21\% trauma, $79 \%$ non-trauma) compared to the corresponding period of January-July 2019 (16\% trauma, $84 \%$ non-trauma).

\section{Inpatient admissions as a proportion of total CE attendance}

For the overall period of January-July, there was a 37\% decrease in number of $\mathrm{CE}$ attendances requiring hospital inpatient admission from 19,629 in January-July 2019 to 12,304 in January-July 2020 . The proportion of CE attendances requiring admission remained similar: $20 \%$ in January-July 2019 and 21\% in January-July 2020.

When analysed by month, inpatient admissions from January-July 2020 (Fig. 4, right column) decreased in tandem with total CE attendance through the first 5 months of the year, then increased throughout the post-circuit breaker period, though not reaching preCOVID-19 levels. The proportion of admissions to total CE attendances increased slightly from $19-21 \%$ in January-April 2020, to 23-24\% in May-July 2020. January-July 2003 (Fig. 4, left column) showed a similar pattern, with monthly inpatient admissions and total CE attendances decreasing during the SARS outbreak and then gradually increasing with outbreak resolution. Although the proportion of admissions to CE attendances decreased slightly from $19-22 \%$ in January-April 2003 to $17-18 \%$ in May-July 2003, it eventually stablised at $16-20 \%$ in late 2003 and throughout 2004. January-July 2019 (Fig. 4, middle column) showed a relatively stable number of admissions, attendances and proportion of admissions to attendances $(20-21 \%)$ throughout the year.

\section{Kawasaki disease admissions}

There was a cumulative total of 78 inpatient admissions for Kawasaki disease from January-July 2020 compared 
Table 2. Comparison of top 10 diagnoses for P1 trauma and non-trauma CE attendances from January-July 2019 and 2020

\begin{tabular}{|c|c|c|}
\hline & $\begin{array}{l}\text { January-July } 2019 \\
\text { Top } 10 \text { diagnoses, n (\%) }\end{array}$ & $\begin{array}{l}\text { January-July } 2020 \\
\text { Top } 10 \text { diagnoses, } n(\%)\end{array}$ \\
\hline P1 Trauma attendances & $\begin{array}{l}\text { Total } 307 \\
\text { Head injuries } 79(25) \\
\text { Road traffic accidents } 58(19) \\
\text { Contusions and superficial injuries } 33 \text { (10) } \\
\text { Lower limb fractures } 21 \text { (7) } \\
\text { Neck and back injuries } 20 \text { (7) } \\
\text { Burns and scalds } 18 \text { (6) } \\
\text { Lacerations } 15(5) \\
\text { Patellar dislocations } 12(4) \\
\text { Falls } 10 \text { (3) } \\
\text { Drowning } 8 \text { (3) }\end{array}$ & $\begin{array}{l}\text { Total } 197 \\
\text { Head injuries } 49 \text { (25) } \\
\text { Road traffic accidents } 36(18) \\
\text { Burns and scalds } 25(13) \\
\text { Contusions and superficial injuries } 16(8) \\
\text { Lower limb fractures } 14(7) \\
\text { Neck and back injuries } 10(5) \\
\text { Patellar dislocations } 10(5) \\
\text { Lacerations } 9(5) \\
\text { Falls } 3(2) \\
\text { Drowning } 3 \text { (2) } \\
\text { Smoke inhalation } 3(2) \\
\text { Upper limb fractures } 3(2)\end{array}$ \\
\hline $\begin{array}{l}\text { P1 Non-trauma } \\
\text { attendances }\end{array}$ & $\begin{array}{l}\text { Total 2,141 } \\
\text { Asthma and wheezing } 461(22) \\
\text { Bronchiolitis } 251(12) \\
\text { Fever including sepsis } 246(11) \\
\text { Seizures including febrile fits } 210(10) \\
\text { Lower respiratory infections } 127(6) \\
\text { Vomiting including cyclical } 111(5) \\
\text { Anaphylaxis and allergic reactions } 87 \text { (4) } \\
\text { Croup and stridor } 49 \text { (2) } \\
\text { Upper respiratory infections } 48 \text { (2) } \\
\text { Supraventricular tachycardia and cardiac arrhythmias } 39 \text { (2) }\end{array}$ & $\begin{array}{l}\text { Total 1,233 } \\
\text { Asthma and wheezing } 187(15) \\
\text { Fever including sepsis } 168(14) \\
\text { Seizures including febrile fits } 138(11) \\
\text { Bronchiolitis } 90 \text { (7) } \\
\text { Lower respiratory infections } 88(7) \\
\text { Anaphylaxis and allergic reactions } 73(6) \\
\text { Vomiting including cyclical } 69(6) \\
\text { Upper respiratory infections } 34(3) \\
\text { Supraventricular tachycardia and cardiac arrhythmias } 34(3) \\
\text { Drug overdose and poisoning } 24(2)\end{array}$ \\
\hline
\end{tabular}

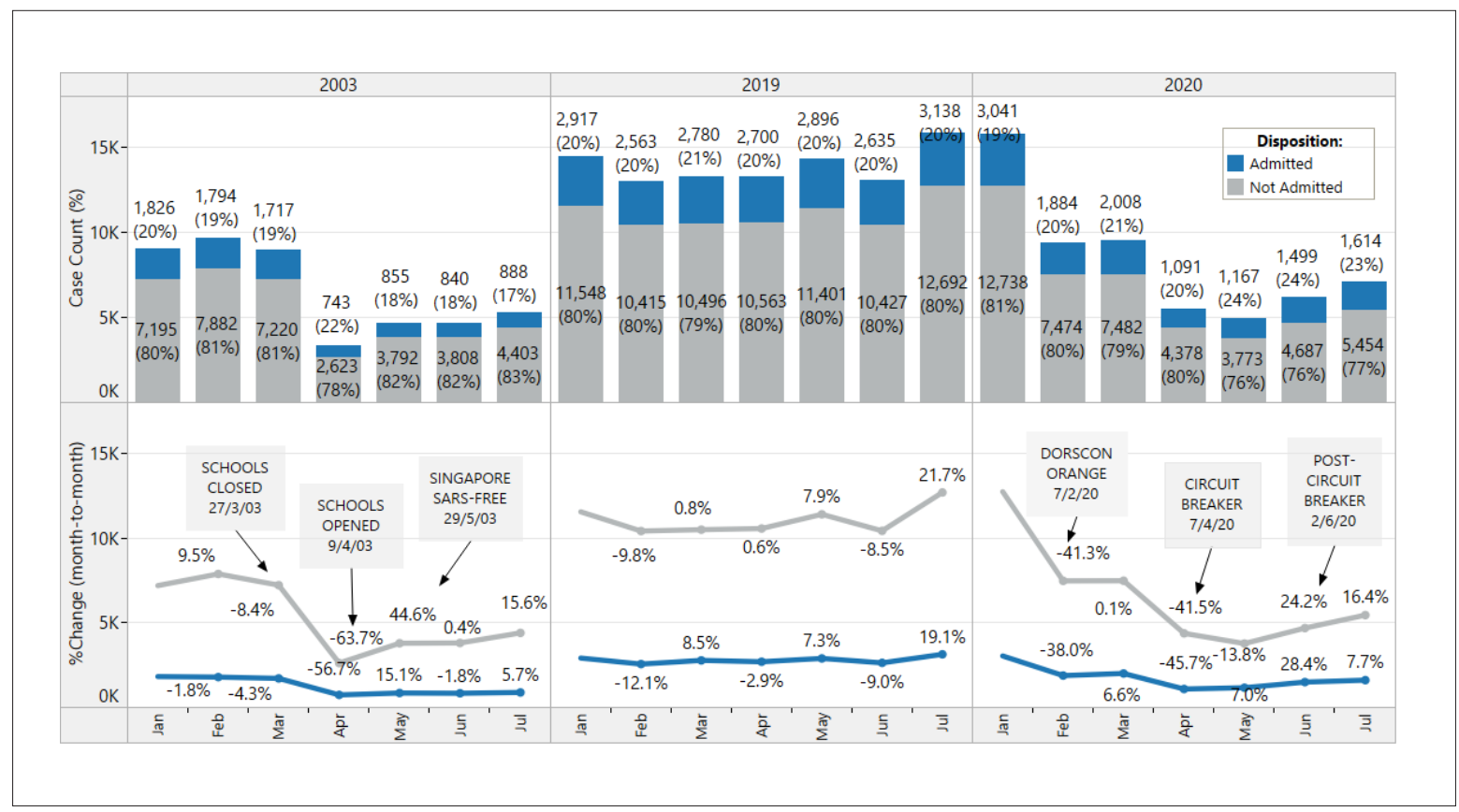

Fig. 4. Monthly inpatient admissions as a proportion of total Children's Emergency attendances, from January-July 2003 (left column), 2019 (middle) and 2020 (right). The top row shows the monthly trend within each year, and the bottom row shows the percentage change in admissions and non-admitted attendances from the previous month, in relation to national policy changes during the 2003 SARS and 2020 COVID-19 outbreaks. DORSCON: Disease Outbreak Response System CONdition.

to 90 admissions from January-July 2019, with a similar admission pattern through the course of both years. From May 2020 onwards, all Kawasaki disease patients were tested for COVID-19; all 49 patients tested to date (either by nasopharyngeal swab PCR, immunoglobulin $\mathrm{G}$ [IgG] serology, or both) were COVID-negative. 
For the whole of 2019 there were 3 patients admitted to the intensive care unit (ICU) for Kawasaki disease shock syndrome, whereas from January-July 2020, 4 patients were admitted to the ICU with Kawasaki disease shock syndrome, all of whom made an uneventful recovery. All 4 Kawasaki disease shock syndrome cases presenting in 2020 were tested for SARS-CoV-2 PCR on presentation (all negative) and one patient additionally had SARS-CoV-2 IgG serology testing 48 hours after presentation (negative). The 3 Kawasaki shock patients who had only SARS-CoV-2 PCR done presented in April 2020, before SARS-CoV-2 IgG testing was routinely done.

\section{DISCUSSION}

Over the course of the 2020 COVID-19 pandemic, paediatric ED overall attendances decreased from January-July 2020 in line with successive "circuit breaker" public health measures, reached a nadir around April-May 2020, then gradually increased once circuit breaker measures were relaxed, albeit not reaching the previous 2019 baseline of around 450 daily attendances. The 2003 SARS outbreak reflected a similar trend in $\mathrm{CE}$ attendances; even after the SARS outbreak was over in July 2003, CE attendances took 2-3 months to return to a new baseline that was lower than preSARS levels for the entire following year of 2004. CE attendances during the outbreak years of 2020 and 2003 stand in contrast to the static pattern seen during their respective pre- and post-outbreak years, 2019 and 2004. Several countries including the US, the UK, Italy and Ireland have likewise reported substantial decreases in paediatric emergency department visits during the COVID-19 pandemic compared to previous years. ${ }^{26-29}$ At this point in the pandemic, there are emerging data from syndromic surveillance in the US and UK on the impact of national and state-level policies that have affected emergency department attendances. ${ }^{26,27}$ Across all age groups, the steepest reductions in ED visits in both these countries were in children below 14 years of age. ${ }^{26,27}$ Considering the changes in population healthcare-seeking behaviour, which differ between adult and paediatric patients, and the consequent potential for pandemic-related delayed presentation of life-threatening conditions in children, it is important to document our collective local paediatric acute healthcare experience from both SARS and COVID-19 pandemics. The intra-pandemic reductions in overall paediatric ED attendances, followed by a prolonged phase before reaching pre-pandemic levels, may have implications for future health services planning, subspecialty expertise and resource allocation.

Once the ED segregated patients into 3 adjacent, physically separate risk-stratified areas from February 2020 onwards, ${ }^{24}$ the high-risk area registered a spike in "suspect" attendances in March 2020, corresponding to the initial surge in COVID-19 swab testing of asymptomatic paediatric close contacts of confirmed COVID-19 cases; the number of "at-risk" attendances in the intermediate-risk area decreased; while the number of "clean" attendances in the low-risk area increased, before stabilising. This overall pattern of equilibration in the respective risk-stratified locations is likely due to progressive restrictions in population activities and movement reducing opportunities for the spread of other non-COVID-19 infectious diseases. Stratifying $\mathrm{CE}$ attendances by triage category (P1, P2 and P3) has shown that despite the ongoing COVID-19 pandemic in 2020 , the proportions of attendances by patient acuity have remained essentially unchanged from the previous year of 2019. Similar observations regarding patient acuity for paediatric ED attendances were made in Ireland..$^{29}$ That the proportions of higher-acuity (P1 and P2) patients are the same in 2019 and 2020 suggests potentially life-threatening paediatric emergencies are still presenting to the ED in a timely manner, rather than delaying medical attention until the child is more unwell, as reported in Italy and the UK. ${ }^{28,30}$ Comparing P1 (highest acuity) attendances in 2019 versus 2020, the simultaneous increase in proportion of P1 burns/scalds patients and decrease in proportion of P1 respiratoryrelated attendances are likely related to extended home confinement and social distancing. Taken together with the decreasing intermediate-risk area attendances (patients with fever or respiratory symptoms) over January-July 2020, these trends are consistent with data from the US and Ireland showing decreases in paediatric respiratory and viral-mediated illnesses during the pandemic. ${ }^{26,29}$ Given the increase in proportion of total $\mathrm{CE}$ attendances classified as trauma cases from $16 \%$ in January-July 2019 to $21 \%$ in January-July 2020, the nature of consults may have shifted in favour of trauma cases.

We initially hypothesised that both CE attendances and inpatient admissions would decrease through the first 5 months of 2020 and increase after circuit breaker measures were lifted; and that the proportion of admissions over $\mathrm{CE}$ attendances would continue to increase throughout 2020. These hypotheses have been borne out by 2020 data: the absolute number of 
CE attendances and inpatient admissions decreased and increased in line with circuit breaker measures; while the proportion of hospital admissions to CE total attendances increased slightly. The 2003 SARS outbreak showed the same trend in CE total attendances, with the opposite trend in proportion of admissions to $\mathrm{CE}$ attendances decreasing slightly over the course of the outbreak. The differences in proportions of admissions may be due to changes in health-seeking behaviour, such as a relative willingness of most parents to seek urgent medical attention when children are unwell, coupled with reluctance to be admitted to hospital for fear of nosocomial infection during the outbreak.

In contrast to the experience in Europe and North America, ${ }^{7-9}$ our findings support preliminary data that no cases of MIS-C or Kawasaki disease have been observed in conjunction with paediatric COVID-19 in Singapore or Asia thus far. ${ }^{10,11,31}$ The reasons for this geographical discrepancy have been postulated to include genetic variation of SARS-CoV-2 and major histocompatibility complex class 1 genes. ${ }^{11}$ In our institution, all paediatric patients with COVID-19 have had a mild disease course, none requiring oxygen supplementation or intensive care. ${ }^{31}$ While it is possible that patients with atypical circulatory collapse may have had remote manifestations of COVID-19 presenting in the form of septic shock or systemic inflammatory response syndrome (SIRS), every attempt was made in our institution to identify potential cases of MIS-C by testing all septic shock and SIRS admissions to the ICU with SARS-CoV-2 PCR on presentation; testing all Kawasaki disease patients at the point of diagnosis with SARS-CoV-2 PCR and IgG serology; and instructing clinicians to test all patients meeting WHO MIS-C criteria for both SARS-CoV-2 PCR and IgG serology.

\section{CONCLUSION}

Nationwide public health measures adopted in Singapore have had an impact on paediatric ED attendances as well as hospital inpatient admissions, in the context of 2 separate worldwide emerging infectious disease outbreaks: SARS in 2003 and COVID-19 in 2020. Considering the inherent limitations in comparing SARS and COVID-19, 2 different healthcare challenges with correspondingly different consequences, it is important to observe attendance patterns as circuit breaker measures are progressively relaxed to monitor for a sustained trend in the reduction of ED attendances, given the more protracted nature of the COVID-19 outbreak versus SARS, and more stringent public health measures required to control spread of COVID-19 that may reduce infections due to behavioural changes in the population as a whole. Further studies are ongoing to evaluate the accuracy of triage criteria, ED resource utilisation, and epidemiology of emergency attendances and hospital admissions. These insights will inform upcoming workflows, processes and structural modifications to future-proof the paediatric ED for a post-COVID-19 era.

\section{REFERENCES}

1. World Health Organization. WHO Director-General's opening remarks at the media briefing on COVID-19 - 11 March 2020, March 2020. Available at: https://www.who.int/director-general/speeches/ detail/who-director-general-s-opening-remarks-at-the-media-briefingon-covid-19---11-march-2020. Accessed on 24 February 2021.

2. World Health Organization. Coronavirus disease (COVID-19) weekly epidemiological update, February 2021. Available at: https://www.who.int/publications/m/item/weekly-epidemiologicalupdate---23-february-2021. Accessed on 24 February 2021.

3. Petersen E, Koopmans M, Go U, et al. Comparing SARS-CoV-2 with SARS-CoV and influenza pandemics. Lancet Infect Dis 2020;20:e238-44.

4. Chan-Yeung M, Xu RH. SARS: epidemiology. Respirology 2003;8:S9-14.

5. CDC COVID-19 Response Team. Coronavirus Disease 2019 in Children - United States, February 12-April 2, 2020. MMWR Morb Mortal Wkly Rep 2020;69:422-6.

6. Dong Y, Mo X, Hu Y, et al. Epidemiology of COVID-19 among children in China. Pediatrics 2020;145:e20200702.

7. Riphagen S, Gomez X, Gonzalez-Martinez C, et al. Hyperinflammatory shock in children during COVID-19 pandemic. Lancet 2020; 395:1607-8

8. Feldstein LR, Rose EB, Horwitz SM, et al. Multisystem inflammatory syndrome in U.S. children and adolescents. N Engl J Med 2020;383:334-46

9. World Health Organization. Multisystem inflammatory syndrome in children and adolescents with COVID-19, May 2020. Available at:https://www.who.int/publications/i/item/multisystem-inflammatorysyndrome-in-children-and-adolescents-with-covid-19. Accessed on 24 February 2021.

10. Yung CF, Nadua KD, Oh BK, et al. Epidemiologic trends in Kawasaki disease during coronavirus disease-19 in Singapore. J Pediatr 2020;226:314-5.

11. Kam KQ, Ong JSM, Lee JH. Kawasaki disease in the COVID-19 era: a distinct clinical phenotype? Lancet Child Adolesc Health 2020;4:642-3.

12. Ministry of Health, Singapore. Confirmed imported case of novel coronavirus infection in Singapore; multi-ministry taskforce ramps up precautionary measures, January 2020. Available at: https://www. moh.gov.sg/news-highlights/details/confirmed-imported-case-ofnovel-coronavirus-infection-in-singapore-multi-ministry-taskforceramps-up-precautionary-measures. Accessed on 24 February 2021.

13. Ng Y, Li Z, Chua YX, et al. Evaluation of the effectiveness of surveillance and containment measures for the first 100 patients with COVID-19 in Singapore - January 2-February 29,2020. Morb Mortal Wkly Rep 2020;69:307-11. 
14. Chen JI, Yap JC, Hsu LY, et al. COVID-19 and Singapore: From early response to circuit breaker. Ann Acad Med Singap 2020;49:561-72.

15. Tan THY, Toh MPHS, Vasoo S, et al. Coronavirus disease 2019 (COVID-19): the Singapore experience. A review of the first eight months. Ann Acad Med Singap 2020;49:764-78.

16. Ministry of Health, Singapore. Risk assessment raised to DORSCON Orange, February 2020. Available at: https://www.moh.gov. sg/news-highlights/details/risk-assessment-raised-to-dorscon-orange. Accessed on 24 February 2021.

17. Ministry of Health, Singapore. Additional border control measures to reduce further importation of COVID-19 cases, March 2020. Available at: https://www.moh.gov.sg/news-highlights/details/ additional-border-control-measures-to-reduce-further-importation-ofcovid-19-cases. Accessed on 24 February 2021.

18. Ministry of Health, Singapore. Circuit breaker to minimise further spread of COVID-19, April 2020. Available at: https://www.moh.gov. sg/news-highlights/details/circuit-breaker-to-minimise-further-spreadof-covid-19. Accessed on 24 February 2021.

19. Ministry of Health, Singapore. Strong national push to stem spread ofCOVID-19, April 2020. Available at: https://www.moh.gov.sg/newshighlights/details/strong-national-push-to-stem-spread-of-covid-19. Accessed on 24 February 2021.

20. Ministry of Health, Singapore. Easing the tighter circuit breaker measures, preparing for gradual resumption of activity after 1 June, May 2020. Available at: https://www.moh.gov.sg/news-highlights/ details/easing-the-tighter-circuit-breaker-measures-preparingfor-gradual-resumption-of-activity-after-1-june. Accessed on 24 February 2021.

21. Ministry of Health, Singapore. End of circuit breaker, phased approach to resuming activities safely, May 2020. Available at: https://www.moh.gov.sg/news-highlights/details/end-of-circuit- breaker-phased-approach-to-resuming-activities-safely. Accessed on 24 February 2021

22. Goh KT, Cutter J, Heng BH, et al. Epidemiology and control of SARS in Singapore. Ann Acad Med Singap 2006;35:301-16.

23. Puthucheary J, D Lim, I Chan, et al. Severe acute respiratory syndrome in Singapore. Arch Dis Child 2004;89:551-6.

24. Tan RM, Ong GY, Chong SL, et al. Dynamic adaptation to COVID-19 in a Singapore paediatric emergency department. Emerg Med J 2020;37:252-4.

25. Ganapathy S, Yeo JG, Thia XH, et al. The Singapore paediatric triage scale validation study. Singapore Med J 2018;59:205-9.

26. Hartnett KP, Kite-Powell A, DeVies J, et al. Impact of the COVID-19 pandemic on emergency department visits - United States, January 1, 2019-May 30, 2020. MMWR Morb Mortal Wkly Rep 2020;69:699-704.

27. Hughes HE, Hughes TC, Morbey R, et al. Emergency Department use during COVID-19 as described by syndromic surveillance. Emerg Med J 2020;37:600-4.

28. Lazzerini M, Barbi E, Apicella A, et al. Delayed access or provision of care in Italy resulting from fear of COVID-19. Lancet Child Adolesc Health 2020;4:e10-e11.

29. Dann L, Fitzsimmons J, Gorman KM, et al. Disappearing act: COVID-19 and paediatric emergency department attendances. Arch Dis Child 2020;105:810-1.

30. Roland D, Harwood R, Bishop N, et al. Children's emergency presentations during the COVID-19 pandemic. Lancet Child Adolesc Health 2020;4:e32-e33.

31. Li J, Thoon KC, Chong CY, et al. Comparative analysis of symptomatic and asymptomatic SARS-CoV-2 infection in children. Ann Acad Med Singap 2020;49:530-7. 